\title{
Determining the factors that affect self-reported quality of life among Turkish seafarers
}

\author{
İsmail Hakkı Demir ${ }^{1}$, Deniz Oruç ${ }^{2}$, Serap Bayram $^{3}(\mathbb{D}$ \\ ${ }^{1}$ Düzce University, Health Research and Application Centre, Düzce, Turkey \\ ${ }^{2}$ Düzce University, Faculty of Health Sciences, Düzce, Turkey \\ ${ }^{3}$ Department of Health and Care Services, Düzce University, Vocational Health School, Düzce, Turkey
}

\begin{abstract}
Background: The purpose of this study is to determine the quality of life (QOL) of Turkish seafarers and its relationship with the factors affecting it.

Materials and methods: A total of 103 Turkish seafarers completed an "Employee Assessment Form" and "WHOQOL-BREF" Scale.

Results: The majority of the seafarers who participated in the study were males (98\%) of the age group $36-48$ (44\%). Among the seamen, $58 \%$ smoked and $42 \%$ used alcohol. The rate of exercising was $29 \%$ and the mean body mass index was $27.63 \pm 3.78$. Average scores of WHOQOL-BREF sub-dimension are $15.99 \pm 1.83$ for physical (PHY), $15.77 \pm 2.26$ for psychological (PSY), $15.50 \pm 2.73$ for social (SOC), $14.17 \pm 2.25$ for environmental domain (ENV), and finally $14.18 \pm 2.13$ for ENV-TR.

Conclusions: According to the results of this study, it is possible to argue that Turkish seafarers have a weak awareness towards improving their health and QOL in their working life and that they need assistance in improving their QOL, especially in psychological and social aspects.
\end{abstract}

(Int Marit Health 2021; 72, 2: 129-137)

\section{Key words: health promotion, nursing, working characteristics, seafarers, Turkey, quality of life}

\section{INTRODUCTION}

Ships and ports are the basic elements of maritime transport. Ships are industrial structures designed and produced to serve a particular purpose. In world maritime transport, about 1.5 million seafarers are employed and the international merchant fleet consist of about 55,000 merchant ships, $85 \%$ of which are oil tankers, bulk carriers and container ships [1]. Maritime activities in Turkey are mostly the transport of people, goods and vehicles, oil survey, container transport, fishing, coast guard and scientific research activities [2]. Turkey has the second rank in the world with 179,828 seafarers and $6.6 \%$ share $[3,4]$. It is necessary for each ship to carry a specific number of seafarers with particular abilities according to its flag, class and size. A ship's complement mainly consists of two departments which are "Deck" and "Engine". According to Regulation on Seafarers and Marine Pilots (2018), seafarers consist of the captain, officers, mariners, and other people employed on the ship [4, 5].

Seafarers are qualified professionals and are at risk of serious injury and death. Forsell et al. (2017) [6] found risk of an accident in deck staff as $67 \%$, among engine crew as $77 \%$, and $64 \%$ for service personnel during last year of service. It is noted that the death rate of Danish seafarers and coastal pilots is 10 times higher than industrial workers. While the average risk of fatal accidents at sea was found to be $6.4 / 100$ years, the average risk of accidents that lead to $5 \%$ or more permanent disabilities was $0.67 / 100$ years [7]. According to data obtained from a study by an Italian marine telemedical centre which provide remote 
assistance for seafarers, 383 deaths were reported in a period of 25 (1.31\%) years. The reasons of death in seafarers were reported as cardiovascular diseases, accidents, contagious diseases, psychoactive factors and respiratory diseases. Average age of death was found as $44.89 \pm 10.53$ [8]. In a follow-up study conducted on German seafarers, crude death rate was reported as 65 per 100,000 seafarer-years. The average age of death was $48.5 \pm 12.7$ and $57.8 \%$ of these included documented records of occupational accidents, suicides and ischaemic heart disease. The rate of fatal accidents proved higher among the staff working on deck and engine room compared to other crew members [9].

During their work on the ship, seafarers are exposed to chemical and physical substances that cause cancer. It was reported that cancer incidence in Finnish seafarers is not different compared to the general male population, however some types of cancers, such as non-melanoma skin cancer was seen 1.6 times, and mesothelioma as 2.9 times more [10].

Cardiovascular diseases are also another serious health problem for seafarers. It was stated that German seafarers have a 10-year coronary heart disease risk similar to the German reference population of the same age (56 against 57 for each 1000 subject); it was expressed that healthy worker effect might affect this prediction [11]. Scovill et al. (2012) [12] reported a high prevalence of obesity (61\%), smoking (41\%), high level of triglycerides (42\%), low level of high density lipoprotein cholesterol (47\%), hypertension (42\%), high fasting blood sugar (22\%) and displaying three or more characteristics of metabolic syndrome among United States (US) inland waterway merchant marine captains and pilots. Among the corps members on US Navy vessels, the prevalence of hyperlipidaemia was found as $21 \%$, hypertension as $26 \%$, smoking as $27 \%$ and obesity was reported to be $13 \%$ [13]. Among Danish male and female seafarers, the prevalence of metabolic syndrome was found as $26 \%$ and $11 \%$, respectively. It was also reported that $31 \%$ had a habit of smoking and 19\% declared high alcohol consumption [14]. In a study conducted on Danish seafarers, it was stated that $44 \%$ smoked, $25 \%$ were obese and $51 \%$ were diagnosed with metabolic syndrome disease [15]. The prevalence of metabolic syndrome among Iranian seafarers was found to be $15 \%$, while common cardio-metabolic risk factors were identified as excessive weight (51\%), abdominal obesity (39\%) and smoking (28\%) [16].

Moreover, musculoskeletal disorders are also common in seafarers due to long working hours, long shifts, poor living conditions, noise, and vibration effects. Among Danish fishermen, the prevalence of pain in all musculoskeletal system areas was found as more than $80 \%$. More than one third $(37 \%)$ reported back pain enduring for at least 30 days. Workload was identified as the only predictor about all pain zones, especially upper and lower extremity pain [17]. It was stated that the rate of hand and arm pain was $24 \%$ due to vibration caused by power tools. Exposure to vibration and noise, ringing in the ears and hearing disorders amount to $83 \%$ among the members of the engine department, $71 \%$ in service personnel and $70 \%$ in deck crew working for Swedish merchant fleet [6]. Besides, vibrations emanating from the ship were found to be the most frequent reason for sleep disorders for $63 \%$ of the engineering personnel aboard vessels in the Royal Norwegian Navy [18].

It was reported that seafarers except for the command staff had a much higher rate of skin diseases and the most common problems were found to be dermatitis and eczema. In the same study, it was found that the incidence of sexually transmitted diseases was significantly higher among Danish seafarers working aboard ships other than passenger liners and among this population especially HIV and hepatitis had increased for 5 years [19].

It was emphasized that seafarers had increased stress and psychological problems related to work. In a study, prevalence of depression among seafarers was found to be $5 \%$ [12]. Borch et al. (2012) [20] reported that $11 \%$ of deaths among Danish seafarers were suicides. The prevalence of stress/depression/anxiety in female seafarers was reported as $43 \%$. In addition, $18 \%$ of female seafarers reported sexual harassment as another issue [16]. Carotenuto et al. (2013) [21] found that compared to deck crew, engine staff had more anxiety and fatigue and lower job satisfaction. It was observed that deck and engine officers had higher self-control levels than the engine crew.

As it is known, health problems do not only emerge from biomedical, social or psychological conditions, but more frequently from lifestyle and behaviour. Health-Related Quality of Life (HRQOL) is a multi-dimensional concept that includes physical, mental, emotional, and social functionality. HRQOL is the general well-being of individuals, measuring positive emotions and life satisfaction. Well-being is a relative condition where the individual maximises his/her physical, mental and social functions in the context of supportive environments to lead a full, satisfying and productive life [22]. A study called Healthy People 2020 performed by US Department of Health and Human Services emphasized the importance of quality of life (QOL) and well-being in the cycle of life [23]. The World Health Organization (WHO) emphasized the importance of individuals' psychosocial and economic productivity along with health and a better QOL [24]. An individual's QOL is directly affected by the occupations that shape both their economic and health life. Seafarers have different characteristics according to their gender, age, physical activity, body mass, nutrition, alcohol/tobacco consumption, and health issues [25]. While they have to cope with long working hours 
and three-shift schedules, they work in poor conditions with high noise levels due to the operations in the engine department. Furthermore, strong and rapid changes in the natural environment at sea make it difficult to sustain homeostasis [26]. However, QOL in seafarers is a new topic which has not been studied sufficiently. Available sources on this topic show results of the World Health Organization Quality of Life Scale (WHOQOL-BREF) on seafarers from various countries. An empirical study on Lithuanian seafarers proved QOL to be at poor-moderate level [27]. In two studies conducted on Polish seafarers, QOL level proved to be high [28, 29]. In Turkey, however, there have been no studies focusing on QOL on seafarers. In Turkey, seafarer's healthcare services are conducted as travel health, health inspections and seafarer's health services, by Directorate General of Health Services for Borders and Coasts of Turkey, associated with the Ministry of Health [30]. However, medical examinations on seafarers are made up of limited examinations and superficial inspections.

In this respect, the purpose of this study is to determine the QOL of Turkish seafarers and its relationship with the factors affecting it. In this study, the QOL was studied especially by using WHOQOL-BREF. The study tried to answer the questions below:

- What is the QOL level in seafarers (using WHOQOL-BREF Scale)?

- Is there a relationship/difference between socio-demographic characteristics, working conditions and health characteristics of seafarers?

\section{SUBJECTS}

\section{MATERIALS AND METHODS}

Sample of the study is seafarers applying for certificate of competence exams in a port authority in Black Sea Region, under the supervision of the Ministry of Transport and Infrastructure. Without conducting sample selection, a total of 103 Turkish seafarers who accepted to participate in the study, $1.9 \%(n=2)$ of whom are female and $98.1 \%$ $(n=101)$ of whom are male, constitute the sample. Out of 200 people who registered to the exam centre, 103 accepted to take part in the study. It is not possible to extrapolate on whether $50 \%$ of seafarers who did not take part in the study have similar characteristics with the sample group, as their demographic information (age, department, rang, gender etc.) was not collected. The study was approved by the Noninvasive Clinical Research Ethical Committee, Faculty of Medicine, Düzce University (03.09.2018, decree no: $2018 / 165)$. A written approval was obtained from the ministry before the study. The purpose of the study was explained to all participants, and their consent was obtained. The study was completed in accordance with the Helsinki Declaration.

\section{STUDY DESIGN}

The study was designed as descriptive, analytical, and cross-sectional in order to determine the factors affecting QOL among Turkish seafarers. Data was gathered from September-December 2018 through "Employee Assessment Form" and "WHOQOL-BREF Scale". It took about 15-20 minutes to fill in the forms for each applicant.

\section{EMPLOYEE ASSESSMENT FORM}

The form includes questions on gender, age, marital status, level of education, maritime transport type, ship's flag, ship's area of activity, seafarer's profession aboard, term of employment, employment type, work hours, history of work accidents, chronic diseases, tobacco and alcohol consumption, exercise habits, daily sleep time and body mass index (BMI).

\section{WORLD HEALTH ORGANIZATION QUALITY OF LIFE SCALE SHORT FORM TURKISH VERSION (WHOQOL-BREF)}

The scale was developed by the WHO. Validity and reliability tests were conducted by Eser et al. (1999) [31] WHOQOL-BREF Scale calculates four domain scores as physical (PHY), psychological (PSY), social (SOC) and environmental domain (ENV). Highest scores in each domain prove a better QOL. The first two questions of QOL scale are not summed with total but examined separately. While the original has 26 questions, Turkish version contains 27 questions. The $27^{\text {th }}$ question in the Turkish version "How would you rate challenges (of peer pressure and control) you face from people close to you (spouse, colleagues, relatives)?" was added to ENV-TR score. The items are rated on a 5-point Likert scale; however, $3^{\text {rd }}, 4^{\text {th }}, 26^{\text {th }}, 27^{\text {th }}$ questions have reversed ratings as their answers include negative statements. The measure score is obtained by calculating the arithmetic average of related items; PHY $(3,4,10,15,16$, $17,18)$, PSY $(5,6,7,11,19,26)$, SOC $(20,21,22)$, ENV $(8,9,12,13,14,23,24,25)$, ENV-TR $(8,9,12,13,14,23$, $24,25,27$ ) and multiplying all four domain scores [32]. In this study, internal consistency of the scale with its sub-dimensions was found as 0.62 for PHY, 0.78 for PSY, 0.65 for SOC and 0.79 for ENV, also 0.77 for ENV-TR, which are all at an acceptable level.

\section{STATISTICAL ANALYSIS}

Data gathered as a result of the study was analysed using SPSS (Statistical package of social science) 21.0. While continuous variables were given as standard deviation of the mean, categorical variables were shown in numbers and percentage. Data normal distribution was assessed through Kolmogorov-Smirnov test. In the reliability test, the internal consistency (Cronbach alpha) of the sub-dimensions 
Table 1. Sociodemographic, health and work environment characteristics of seafarers $(n=103)$

\begin{tabular}{|c|c|c|}
\hline Variables & Number or mean \pm standard deviation & Per cent* or range \\
\hline \multicolumn{3}{|l|}{ Sex: } \\
\hline Female & 2 & 1.9 \\
\hline Male & 101 & 98.1 \\
\hline Age [years]: & $39.29 \pm 9.43$ & $23-62$ \\
\hline $23-35$ & 41 & 39.8 \\
\hline $36-48$ & 45 & 43.7 \\
\hline 49 and over & 17 & 16.5 \\
\hline \multicolumn{3}{|l|}{ Marital status: } \\
\hline Married & 70 & 68.0 \\
\hline Single & 33 & 32.0 \\
\hline Children & 64 & 62.1 \\
\hline \multicolumn{3}{|l|}{ Level of education: } \\
\hline Primary-Secondary & 18 & 17.5 \\
\hline High school & 52 & 50.5 \\
\hline University degree & 33 & 32.0 \\
\hline Having chronic diseases & 12 & 11.7 \\
\hline Daily sleep time [h] & $7.19 \pm 1.21$ & $4-10$ \\
\hline Body mass index $\left[\mathrm{kg} / \mathrm{m}^{2}\right]$ : & $27.63 \pm 3.78$ & $18.50-39.18$ \\
\hline Normal weight (18.5-24.99) & 23 & 22.3 \\
\hline Overweight (25.00-29.99) & 57 & 55.3 \\
\hline Obese $(>30.00)$ & 23 & 22.3 \\
\hline Term of employment [month] & $155.92 \pm 111.49$ & $2-468$ \\
\hline Daily working hours [h] & $14.89 \pm 7.29$ & $4-24$ \\
\hline \multicolumn{3}{|l|}{ Employment type: } \\
\hline Full time & 32 & 31.1 \\
\hline Shift/watch & 71 & 68.9 \\
\hline \multicolumn{3}{|l|}{ Maritime transport type: } \\
\hline Bulk carrier & 53 & 51.5 \\
\hline Multi-purpose & 15 & 14.6 \\
\hline Tugboat & 25 & 24.3 \\
\hline Other (fishing-passenger-yacht-pilot vessel) & 10 & 9.7 \\
\hline \multicolumn{3}{|l|}{ Flag type: } \\
\hline Turkey & 79 & 76.7 \\
\hline Other & 24 & 23.3 \\
\hline \multicolumn{3}{|l|}{ Area of activity: } \\
\hline Transoceanic & 36 & 35.0 \\
\hline Seas & 14 & 13.6 \\
\hline Inland waters (straits and gulf) & 53 & 51.5 \\
\hline \multicolumn{3}{|l|}{ Profession: } \\
\hline Command staff & 32 & 31.1 \\
\hline Engine staff & 38 & 36.9 \\
\hline Deck officers & 29 & 28.2 \\
\hline Stewards department & 4 & 3.9 \\
\hline Having work accidents (in the last year) & 16 & 15.5 \\
\hline
\end{tabular}

* Line percentages are given

for WHOQOL-BREF Scale was calculated. In comparison of medians, Mann-Whitney U, Kruskal-Wallis H, Spearman's rho tests were used. Results were within reliability range of $95 \%$, significance was at a level of $p<0.05$.

\section{RESULTS}

Considering the sample of seafarers, $98.1 \%$ were male, $43.7 \%$ were within the age range of $36-48$ (average of age was
$39.29 \pm 9.43$ ), $68 \%$ was married and $62.1 \%$ had children. The rate of chronic diseases was $11.7 \%$. Of all the participants, $58.3 \%$ of them smoke, $41.7 \%$ drink alcohol. BMl average was $27.63 \pm$ $\pm 3.80 \mathrm{~kg} / \mathrm{m}^{2}$. Flag type was Turkey for $76.7 \%$ of them and $51.5 \%$ work in inland waterways (In the straits and gulfs of the Marmara Sea). Regarding the professions aboard, 36.9\% $(n=38)$ were engine department staff. The incidence rate of occupational accidents for seafarers in the last year was $15.5 \%$ (Table 1). 
Table 2. WHOQOL-BREF subdimension average scores for seafarers $(n=103)$

\begin{tabular}{llll}
\hline Domain & Mean \pm standard deviation & Minimum & Maximum \\
\hline Physical domain & $15.99 \pm 1.83$ & 10.29 & 20.00 \\
Psychological domain & $15.77 \pm 2.26$ & 8.00 & 20.00 \\
Social domain & $15.50 \pm 2.73$ & 8.00 & 20.00 \\
Environmental domain & $14.17 \pm 2.25$ & 7.50 & 19.50 \\
Environmental Turkish domain & $14.18 \pm 2.13$ & 8.44 & 19.11
\end{tabular}

Table 3. Correlation of WHOQOL-BREF subdimension scores for seafarers $(n=103)$

\begin{tabular}{|c|c|c|c|c|c|}
\hline Variables* & $\begin{array}{l}\text { Physical } \\
\text { domain }\end{array}$ & $\begin{array}{l}\text { Psychological } \\
\text { domain }\end{array}$ & $\begin{array}{l}\text { Social } \\
\text { domain }\end{array}$ & $\begin{array}{l}\text { Environmental } \\
\text { domain }\end{array}$ & $\begin{array}{l}\text { Environmental } \\
\text { Turkish domain }\end{array}$ \\
\hline Physical domain & 1 & $0.559 * *$ & $0.449 * *$ & $0.445 * *$ & $0.453 * *$ \\
\hline Psychological domain & & 1 & $0.641 * *$ & $0.534 * *$ & $0.528 * *$ \\
\hline Social domain & & & 1 & $0.527 * *$ & $0.512 * *$ \\
\hline Environmental domain & & & & 1 & $0.966 * *$ \\
\hline Environmental Turkish domain & & & & & 1 \\
\hline
\end{tabular}

In Table 2, WHOQOL-BREF sub dimension scores of seafarers are given. Average scores are $15.99 \pm 1.83$ for PHY, $15.77 \pm 2.26$ for PSY, $15.50 \pm 2.73$ for SOC, $14.17 \pm$ \pm 2.25 for ENV, and finally $14.18 \pm 2.13$ for ENV-TR.

The analysis of the interrelationships of WHOQOL-BREF sub-dimensions showed PHY and PSY (0.559) were at a moderate level, positively and significantly correlated. PSY and SOC (0.641), ENV (0.543) and ENV-TR (0.528) were at moderate level, positively and significantly correlated. SOC and ENV (0.527) and ENV-TR (0.512) were at moderate level $(p=0.000)$ (Table 3$)$.

According to the comparisons made within the sample, in seafarers without children, PHY (-2.378; 0.017) and ENV $(-2.265 ; 0.024)$ mean scores were significantly higher than in participants with children. According to BMI value, it was seen that ENV-TR (7.361; 0.025) mean score of overweight seafarers was higher than that of seafarers with normal weight. SOC mean score of seafarers working on bulk carriers was significantly different compared to seafarers working on tugboats $(11.919 ; 0.008)$. For flag types other than Turkey, PHY (-2.705; 0.007), SOC (-2.089; $0.037)$ and ENV-TR (-2.189; 0.029) were significantly higher compared to Turkish flag. As the perception of participants towards QOL rose, WHOQOL-BREF all sub domain scores also increased $(p<0.05)$ (Table 4$)$.

\section{DISCUSSION}

It is essential for a seafarer to be healthy physically and mentally to work at seas. Furthermore, it is necessary to maintain physical health during the period of medical certificate obtained every 2 years. Seafaring is not about a maritime adventure or exploration of the globe as it used to be, but a profession that requires modern technology and difficult conditions such as high working pace and being away from family for an extended period [33]. Working on a ship means a tough working period with many possible health risks. Moreover, health is a means of life for seafarers and there is a need for a health-based approach [26]. There is a need for the application of approaches where occupational health nurses play an active role in studies on improving marine crew health and QOL [34]. Ships are convenient places where health improvement programmes can be applied. Factors such as employees' involuntarily spending their shifts and leisure time on deck, the possibility to contact all other members of the crew at the same time, ability to provide support and interaction among peers, ease of receiving feedback on the effects of the programme and the ability to re-evaluate it make ships an ideal place to apply health improvement programmes successfully.

In this study, it can be concluded that Turkish seafarers are a young population at a productive age with family relations but with a medium level of education, according to their socio-demographic characteristics. While PHY and PSY are higher in women, SOC, ENV and ENV-TR domain scores are higher in men. $\mathrm{PHY}$ is higher for people aged 36-48, while PSY, SOC, ENV and ENV-TR scores are higher for people aged 49 and over. Similarly, in a study conducted on Lithuanian seafarers, PHY was found to be higher between 
Table 4. Comparison of WHOQOL-BREF subdimension scores of seafarers with sociodemographic characteristics $(n=103)$

\begin{tabular}{|c|c|c|c|c|c|}
\hline Characteristics & $\begin{array}{l}\text { Physical } \\
\text { domain }\end{array}$ & $\begin{array}{l}\text { Psychological } \\
\text { domain }\end{array}$ & $\begin{array}{l}\text { Social } \\
\text { domain }\end{array}$ & $\begin{array}{l}\text { Environmental } \\
\text { domain }\end{array}$ & $\begin{array}{l}\text { Environmental } \\
\text { Turkish domain }\end{array}$ \\
\hline \multicolumn{6}{|l|}{ Having children } \\
\hline Yes & $15.66 \pm 1.95$ & $15.64 \pm 2.34$ & $15.29 \pm 2.84$ & $13.77 \pm 2.43$ & $13.85 \pm 2.33$ \\
\hline No & $16.53 \pm 1.48$ & $16.00 \pm 2.12$ & $15.83 \pm 2.53$ & $14.82 \pm 1.76$ & $14.74 \pm 1.63$ \\
\hline Test statistic* & -2.378 & -0.390 & -0.841 & -2.265 & -1.839 \\
\hline $\mathrm{p}$ & 0.017 & 0.697 & 0.400 & 0.024 & 0.066 \\
\hline \multicolumn{6}{|l|}{ Daily sleep time } \\
\hline Test statistic $* * *$ & 0.200 & 0.061 & 0.189 & 0.166 & 1.153 \\
\hline $\mathrm{p}$ & 0.043 & 0.539 & 0.056 & 0.094 & 0.123 \\
\hline \multicolumn{6}{|l|}{ Body mass index class } \\
\hline Normal weight (1) & $16.17 \pm 1.46$ & $15.51 \pm 2.29$ & $15.42 \pm 2.81$ & $13.26 \pm 2.24$ & $13.26 \pm 2.14$ \\
\hline Overweight (2) & $16.18 \pm 1.48$ & $16.09 \pm 1.85$ & $15.42 \pm 2.81$ & $14.65 \pm 1.93$ & $13.87 \pm 2.75(1)$ \\
\hline Obese (3) & $15.33 \pm 2.70$ & $15.25 \pm 2.99$ & $15.65 \pm 2.20$ & $13.90 \pm 2.75$ & $13.99 \pm 2.57$ \\
\hline Test statistic ** & 1.569 & 1.238 & 0.263 & 5.727 & 7.361 \\
\hline $\mathrm{p}$ & 0.456 & 0.538 & 0.877 & 0.057 & 0.025 \\
\hline \multicolumn{6}{|l|}{ Type of transport } \\
\hline Bulk carrier (1) & $16.26 \pm 1.77$ & $16.03 \pm 2.46$ & $16.05 \pm 2.69(3)$ & $14.58 \pm 2.27$ & $14.52 \pm 2.13$ \\
\hline Multi-purpose (2) & $15.47 \pm 2.32$ & $15.51 \pm 1.81$ & $16.18 \pm 1.88$ & $13.97 \pm 1.78$ & $13.99 \pm 1.68$ \\
\hline Tugboat (3) & $16.00 \pm 1.48$ & $15.84 \pm 1.65$ & $14.67 \pm 2.37$ & $13.88 \pm 1.95$ & $13.99 \pm 1.99$ \\
\hline Other (4) & $15.31 \pm 2.08$ & $14.67 \pm 2.90$ & $13.60 \pm 3.65$ & $12.95 \pm 3.12$ & $13.20 \pm 2.88$ \\
\hline Test statistic ** & 4.623 & 4.857 & 11.919 & 4.300 & 6.659 \\
\hline $\mathrm{p}$ & 0.202 & 0.183 & 0.008 & 0.231 & 0.447 \\
\hline \multicolumn{6}{|l|}{ Ship's flag } \\
\hline Turkey & $15.73 \pm 1.82$ & $15.66 \pm 2.30$ & $15.36 \pm 2.66$ & $13.96 \pm 2.10$ & $13.98 \pm 1.961$ \\
\hline Other & $16.86 \pm 1.61$ & $16.14 \pm 2.13$ & $15.94 \pm 2.95$ & $14.85 \pm 2.63$ & $4.85 \pm 2.52$ \\
\hline Test statistic* & -2.705 & -0.891 & -1.296 & -2.089 & -2.189 \\
\hline $\mathrm{p}$ & 0.007 & 0.373 & 0.195 & 0.037 & 0.029 \\
\hline \multicolumn{6}{|l|}{ Employment type } \\
\hline Full-time & $15.32 \pm 1.91$ & $15.13 \pm 2.56$ & $15.04 \pm 3.46$ & $13.47 \pm 2.53$ & $13.53 \pm 2.31$ \\
\hline Shift/watch & $16.29 \pm 1.73$ & $16.07 \pm 2.05$ & $15.70 \pm 2.32$ & $14.48 \pm 2.06$ & $14.48 \pm 1.98$ \\
\hline Test statistic* & -2.244 & -1.438 & -0.576 & -1.758 & -2.235 \\
\hline$p$ & 0.025 & 0.150 & 0.565 & 0.079 & 0.042 \\
\hline \multicolumn{6}{|l|}{ Perception of quality of life } \\
\hline A little bad (1) & $11.89 \pm 1.87(2,3,4)$ & $11.33 \pm 3.50(3,4)$ & $11.20 \pm 3.35(3,4)$ & $10.40 \pm 2.46(3,4)$ & $10.84 \pm 2.05(3,4)$ \\
\hline Neither good, nor bad (2) & $15.76 \pm 1.36(3,4)$ & $15.50 \pm 1.88(3)$ & $15.34 \pm 2.64$ & $13.66 \pm 1.88(3)$ & $13.65 \pm 1.76(3)$ \\
\hline Quite good (3) & $17.06 \pm 1.70(4)$ & $16.89 \pm 1.35$ & $16.35 \pm 2.08$ & $15.74 \pm 1.58$ & $15.79 \pm 1.50$ \\
\hline Very good (4) & $17.71 \pm 0.00$ & $18.33 \pm 2.91$ & $17.67 \pm 1.68$ & $16.75 \pm 2.10$ & $16.56 \pm 2.13$ \\
\hline Test statistic ** & 31.210 & 21.670 & 13.767 & 34.921 & 38.239 \\
\hline $\mathrm{p}$ & 0.000 & 0.000 & 0.003 & 0.000 & 0.000 \\
\hline \multicolumn{6}{|l|}{$\begin{array}{l}\text { Perception of satisfaction } \\
\text { with health }\end{array}$} \\
\hline A little satisfied (1) & $12.19 \pm 1.83(3,4)$ & $12.11 \pm 3.56(3,4)$ & $11.11 \pm 3.34(3,4)$ & $10.58 \pm 3.18(3,4)$ & $10.89 \pm 2.68(3,4)$ \\
\hline Not very satisfied (2) & $15.37 \pm 1.42(3,4)$ & $15.14 \pm 2.04(4)$ & $14.85 \pm 2.36(4)$ & $13.22 \pm 1.88(3,4)$ & $13.31 \pm 1.85(3,4)$ \\
\hline Quite satisfied (3) & $16.62 \pm 1.43(4)$ & $16.16 \pm 1.65(4)$ & $15.91 \pm 2.41(4)$ & $14.88 \pm 1.80(4)$ & $14.89 \pm 1.75(4)$ \\
\hline Very satisfied (4) & $17.23 \pm 1.25$ & $17.90 \pm 1.27$ & $17.85 \pm 3.39$ & $15.92 \pm 1.17$ & $15.62 \pm 1.23$ \\
\hline Test statistic** & 34.960 & 25.369 & 26.021 & 30.494 & 27.239 \\
\hline $\mathrm{p}$ & 0.000 & 0.000 & 0.000 & 0.000 & 0.000 \\
\hline
\end{tabular}

*Mann-Whitney U (z); **Kruskall-Wallis H $\left(\chi^{2} \mathrm{KW}\right) ; * * \star S p e a r m a n ' s$ rho $(\mathrm{r})$

the ages of 20 and 24, and PSY proved to be better in seafarers aged 20-24 and 25-34 [35]. Another study on Lithuanian seafarers showed that while PHY, PSY, ENV and total QOL are the highest among seafarers aged 20-24, they are at the lowest among seafarers aged 55-64 [27]. QOL is higher in all subdimensions for both single seafarers and employees without children. Furthermore, there is a significant difference in ENV scores of seafarers without children. While PHY, ENV and ENV-TR scores are higher for people with a university degree, PSY and SOC scores are higher in seafarers with primary school education. 
In this study, QOL scores among Turkish seafarers were 15.99 for PHY, 15.77 for PSY, 15.50 for SOC, 14.17 for ENV and 14.18 for ENV-TR. There were moderate significant positive correlations between PHY and PSY, SOC, ENV and ENV-TR domains; between PSY and SOC, ENV, ENV-TR; and between SOC and ENV, ENV-TR domains. In a study conducted on Polish seafarers, QOL level proved to be high and the scores were respectively, SOC (16.27), PSY (15.62), ENV (15.51) and PHY (14.63). The strongest correlation among QOL domains was noted between $\mathrm{PHY}$ and PSY, and it was stated that the level of SOC could be related to good personal relationships and social support [28]. Another study on Polish seafarers, QOL domain scores were found as SOC (16.48), ENC (15.64), PSY (15.17) and PHY (13.54) [29]. While both studies show PHY as the lowest, in this study PHY scored the highest. This may be due to the fact that Turkish seafarers are at a young age and have fewer health issues. On the other hand, while SOC level ranked the first in two studies, SOC ranked the third in this study. This indicates that the need for programmes towards improving their psychosocial health has increased due to the increase of fatigue, psychiatric diseases (depression, suicide) and other stress-related issues.

The seafarers' level of perception of their own QOL was found to be at a moderate (neither good, nor bad) level (65\%). Being satisfied with one's own health was found mostly (46\%) to be at a good level (very satisfied). Leszczynska et al. (2014) [35] noted that there was a strong significant correlation between the presence of health issues and dynamics of stress, and that there was a significant negative relationship between perceived level of health and again dynamics of stress. They also reported the perceived health median as 8 (between 0 and 10). In this respect, Turkish seafarers' high satisfaction of their own health and their low perception of their QOL do not match. The most important starting point of efforts to improve QOL is the elevation of health level. Their subjective perception of good health may have prevented them from efforts to improve their QOL. While PHY, PSY, ENV and ENV-TR levels are significantly different and high for people who perceive their QOL as "very good", SOC level is highly significantly different. Considering satisfaction of one's own health, QOL level is significantly different for people who answered "very satisfied", compared to others.

In this study, the rate of seafarers with at least one chronic disease was found to be $12 \%$. The rate of Polish seafarers working on an oil rig was $62 \%$ [36]. The prevalence of having one or more chronic health issues is $42 \%$ among mariners in the US Navy [13]. Compared to this rate, Turkish seafarers have fewer chronic diseases. The level of QOL is better in all dimensions among people without chronic diseases compared to the people suffering from one.
The rate of smoking among seafarers is about $58 \%$, alcohol use is $42 \%$. The rates in this study, compared to other study results, were quite high [12, 14-16]. While PHY, SOC, ENV and ENV-TR scores are higher in non-smokers, PSY level is high for smokers. For alcohol users PHY, PSY, ENV and ENV-TR levels are high, but SOC level was found to be lower. Rate of doing exercise in Turkish seafarers is around 29\%. While PHY, PSY and SOC levels are higher for seafarers doing exercise, ENV and ENV-TR domain scores of QOL are higher for people who do not exercise. In their study, Hjarnoe and Leppin (2013) [15] stated that there were no differences between physical activities of seafarers on land and aboard.

For the sleep time of seafarers, average daily sleep time was reported as 7 hours. The most important causes of sleep disorder on ships were noted as noise, vibration, caffeine or use of tobacco products [19]. There is a weak, positive, and significant correlation between sleep time and PHY level only.

Body mass index average of seafarers was found as 28 . While the rate of overweight seafarers is $55 \%$, the rate of obesity is $22 \%$. In other studies, there were varying results $[12,13,15,16,36]$. ENV-TR score is significantly different between the overweight and normal weight seafarers. Romero-Paredes et al. (2016) [37] observed that $14 \%$ of seafarers who were suggested a more appropriate diet and physical exercise had decreased levels of BMI and cholesterol. This result is important in that it shows the effect of health improvement programmes focusing on diet and nutrition that is to be conducted on ships.

While PHY, PSY, ENV and ENV-TR levels were high for people working on bulk carriers, SOC levels of the people working on these ships were significantly higher than people working on tugboats. PSY and SOC levels were higher for people working on foreign ships compared to people on ships with Turkish flag; PHY, ENV and ENV-TR were significantly different. This result was interpreted in the manner that organizational support towards the health and well-being of employees working for maritime businesses belonging to ships with foreign flags were more effective.

Considering the area of activity of the ships, $52 \%$ work at inland waters and 35\% work overseas. Especially for personnel working on overseas lines, the condition of being away from ports and working for longer hours gets more frequent. While it may be safe to assume that this situation might affect their health negatively, it did not make a significant difference on their QOL levels. However, while PHY levels were higher for people working overseas, PSY, SOC, ENV and ENV-TR levels were higher for people working at sea.

In this study, the employment type of $69 \%$ was shift/watch. Average work time was 13 years; daily working period was approximately 15 hours. When daily working 
and sleeping periods of seafarers are considered, most of them did not have enough time for meals and leisure (about 2 hours in total). These reports from seafarers show that the conditions are not in accordance with the standards of training, certification and watchkeeping and are concerning. QOL levels of employees doing shift work were higher than full-time workers in all domains. Furthermore, the difference in PHY and ENV-TR domains was significant for shift workers. However, there was no significant correlation between QOL subdomain levels and working time or daily working hours. When the profession on the ship is considered, most participants were engine and command staff (37\%, 31\%, respectively), a smaller group worked in deck services department (28\%) and the smallest section was found to be stewards department (assisted services). While a difference in health risks and characteristics for different department staff was expected, this situation made no difference on QOL in this study. However, while PHY, ENV-TR levels were high in command staff, PSY, SOC and ENV levels were better for people working in assisted services.

Rate of occupational accidents among seafarers was $16 \%$ in the last year. The accident rate among Turkish seafarers proved to be lower compared to the research of Forsell et al. [6]. Having experienced a work accident did not make a significant difference on any of QOL sub domains. However, while PSY, SOC, ENV and ENV-TR levels were high for people with an occupational accident history, PHY level was higher for people without it.

Seafaring is a risky occupation considering the health and welfare of seafarers. The results of this study confirm the need for health improvement interventions such as quitting smoking, healthy nutrition, and physical exercise programmes, which could bring about a better lifestyle. The challenge here is the necessity of taking particular seafaring conditions into consideration while applying these improvements.

\section{CONCLUSIONS}

In conclusion, it is possible to argue that Turkish seafarers have a weak awareness towards improving their health and QOL in their working life and that they need assistance in improving their QOL, especially in psychological and social aspects. Occupational health services for seafarers in Turkey are; (1) port health services where ship environment risks are observed and health trainings for personnel are conducted, (2) travel health services where immunisation services are performed, (3) health services which perform medical examinations needed to become a seafarers and continue working on the ship, and (4) $7 / 24$ telehealth services for ships en route. Nurses are considered as a profession group within health officers on the ship and named "health personnel" in telehealth ser- vices. However, there are no details regarding the nature of nursing services.

In this respect, it is suggested that ship health models which also include occupational health nurses should be developed in order to improve work environment conditions of Turkish seafarers and their health and to conduct consultancy programmes and observations. When designing these models, medical and health care should be integrated to port health and telehealth services. Thus, it will be possible for seamen to receive not only medical care, but also health care involving QOL.

\section{NOTE}

This study was presented as an oral presentation and published as a summary at the $5^{\text {th }}$ International Healthy Living Congress (Istanbul, Turkey) on April 27-28, 2021.

\section{REFERENCES}

1. Istanbul and Marmara, Aegean, Mediterranean and Black Sea Regions Chamber of Shipping (IMAMB). Maritime industry report. 2019. https://www.denizticaretodasi.org.tr/Media/SharedDocuments/ sektorraporu/2019_sektor_tr.pdf (Accessed March 21, 2019).

2. Topçu G. Determination of Vibration Exposure of Seamen and Precautions to Be Taken Ministry of Labour and Social Security, Directorate General of Occupational Health and Safety. The Ministry of Labor and Social Security. General Directorate of Occupational Health and Safety. Occupational Health and Safety Thesis. Supervisor: Ahmet Nazlığlu, 2016.

3. Republic of Turkey. Maritime transport and Communications Ministry. Us who access Turkey. 2014. http://www.udhb.gov.tr/images/ hizlierisim/868bb671022da8b.pdf (Accessed July 16, 2019).

4. Official Gazette of the Republic of Turkey. Seafarers and pilots regulation. 2018. https://www.resmigazete.gov.tr/eskiler/2018/02/20180210-9.htm (Accessed March 25, 2019).

5. Yilmaz F, İlhan MA. research on occupational health and safety status in Turkish maritime sector (on board ships). J Gazi University Health Sciences. 2018; 3: 25-41.

6. Forsell K, Eriksson $\mathrm{H}$, Järvholm B, et al. Work environment and safety climate in the Swedish merchant fleet. Int Arch Occup Environ Health. 2017; 90(2): 161-168, doi: 10.1007/s00420-016-1180-0, indexed in Pubmed: 27815725.

7. Hansen HL, Nielsen D, Frydenberg M. Occupational accidents aboard merchant ships. Occup Environ Med. 2002; 59(2): 85-91, doi: 10.1136/oem.59.2.85, indexed in Pubmed: 11850550.

8. Grappasonni I, Petrelli F, Amenta F. Deaths on board ships assisted by the Centro Internazionale Radio Medico in the last 25 years. Travel Med Infect Dis. 2012; 10(4): 186-191, doi: 10.1016/j. tmaid.2012.06.006, indexed in Pubmed: 22819258.

9. Oldenburg M, Herzog J, Harth V. Seafarer deaths at sea: a German mortality study. Occup Med (Lond). 2016; 66(2): 135-137, doi: 10.1093/occmed/kqv153, indexed in Pubmed: 26409049.

10. Saarni H, Pentti J, Pukkala E. Cancer at sea: a case-control study among male Finnish seafarers. Occup Environ Med. 2002; 59(9): 613-619, doi: 10.1136/oem.59.9.613, indexed in Pubmed: 12205234.

11. Oldenburg $M$, Jensen $H J$, Latza U, et al. Coronary risks among seafarers aboard German-flagged ships. Int Arch Occup Environ Health. 2008; 81(6): 735-741, doi: 10.1007/s00420-007-0261-5, indexed in Pubmed: 17909838. 
12. Scovill SM, Roberts TK, McCarty DJ. Health characteristics of inland waterway merchant marine captains and pilots. Occup Med (Lond). 2012; 62(8): 638-641, doi: 10.1093/occmed/kqs156, indexed in Pubmed: 22987812.

13. Hurd ES, Rockswold PD, Westphal RJ. Comparison of chronic disease prevalence between U.S. Navy ships without medical doctors and a similar shore-based population. Mil Med. 2013; 178(5): 543-548, doi: 10.7205/MILMED-D-12-00295, indexed in Pubmed: 23756014.

14. Møller Pedersen SF, Jepsen JR. The metabolic syndrome among Danish seafarers. Int Marit Health. 2013; 64(4): 183-190, doi: 10.5603/imh.2013.0002, indexed in Pubmed: 24408138.

15. Hjarnoe L, Leppin A. A risky occupation? (Un)healthy lifestyle behaviors among Danish seafarers. Health Promot Int. 2014; 29(4): 720-729, doi: 10.1093/heapro/dat024, indexed in Pubmed: 23630132.

16. Baygi F, Jensen O, Qorbani M, et al. Prevalence and associated factors of cardio-metabolic risk factors in Iranian seafarers. Int Marit Health. 2016; 67(2): 59-65, doi: 10.5603/imh.2016.0013.

17. Berg-Beckhoff G, Østergaard H, Jepsen J. Prevalence and predictors of musculoskeletal pain among Danish fishermen - results from a cross-sectional survey. J Occ Med Toxicol. 2016; 11(1), doi: 10.1186/s12995-016-0140-7.

18. Sunde E, Irgens-Hansen K, Moen BE, et al. Noise and exposure of personnel aboard vessels in the Royal Norwegian Navy. Ann Occup Hyg. 2015; 59(2): 182-199, doi: 10.1093/annhyg/meu075, indexed in Pubmed: 25324560.

19. Kaerlev L, Jensen A, Hannerz H. Surveillance of hospital contacts among Danish seafarers and fishermen with focus on skin and infectious diseases-a population-based cohort study. Int J Environ Res Public Health. 2014; 11(11): 11931-11949, doi: 10.3390/ ijerph111111931, indexed in Pubmed: 25411726.

20. Borch DF, Hansen HL, Burr H, et al. Surveillance of maritime deaths on board Danish merchant ships, 1986-2009. Int Marit Health. 2012; 63(1): 7-16, indexed in Pubmed: 22669807.

21. Carotenuto A, Fasanaro AM, Molino I, et al. The Psychological General Well-Being Index (PGWBI) for assessing stress of seafarers on board merchant ships. Int Marit Health. 2013; 64(4): 215-220, doi: 10.5603/imh.2013.0007, indexed in Pubmed: 24408143.

22. Kobau R, Sniezek J, Zack M, et al. Well-Being Assessment: An Evaluation of Well-Being Scales for Public Health and Population Estimates of Well-Being among US Adults. Health Well-Being. 2010; 2(3): 272-297, doi: 10.1111/j.1758-0854.2010.01035.x.

23. Healthy People 2020 Framework. The Vision, Mission and Goals of Healthy People 2020. Overarching Goals. http://healthypeople. gov/2020/Consortium/HP2020Framework.pdf [PDF - 254KB] (Accessed November 20, 2019).
24. World Health Organization (WHO). WHOQOL Measuring Quality Of Life. Division of mental health and prevention of substance abuse. 1997. who.int/mental_health/medio/68.pd8 (Accessed August 15, 2019).

25. Aikaterini D, Vasileios $P$, Aris $C$, et al. Seafarers' health problems, emergencies, diseases and risk factors. A systematic review of the literature. Int J Med Health Res. 2019; 5: 43-48.

26. Kim JH, Jang SN. Seafarers' quality of life: organizational culture, self-efficacy, and perceived fatigue. Int J Environ Res Public Health. 2018; 15(10): 2150, doi: 10.3390/ijerph15102150, indexed in Pubmed: 30274349.

27. Malakauskiene R. Health related quality of life among seamen-focus on Lithuanian seamen. Blekinge Institute of Technology. School of Health Science. Master thesis (Supervisor:Karin Holmén). 2006. http://www.diva-portal.org/smash/get/diva2:831664/ FULLTEXT01.pdf.

28. Jeżewska M, Grubman-Nowak M, Moryś J. Quality of life at sea in Polish seafarer's evaluation. Int Marit Health. 2015; 66(4): 247-251, doi: 10.5603/IMH.2015.0046, indexed in Pubmed: 26726896.

29. Jeżewska M, Leszczyńska I, Grubman-Nowak M. Personality and temperamental features vs. quality of life of Polish seafarers. Int Marit Health. 2013; 64(2): 101-105, indexed in Pubmed: 2378822.

30. Republic of Turkey Ministry of Health General Directorate of Border and Coastal Turkey. https://www.hssgm.gov.tr (Accessed August 20, 2020).

31. Eser $\mathrm{E}$, Fidaner $\mathrm{H}$, Fidaner $\mathrm{C}$, et al. Psychometric properties of WHOQOL-100 and WHOQOL-BREF. 3P Dergisi. 1999; 7: 23-40.

32. Eser SY, Fidaner $\mathrm{H}$, Fidaner $\mathrm{C}$, et al. Measure of quality of life WHOQOL-100 and WHOQOL-BREF. 3P Dergisi. 1999; 7: 5-13.

33. Juozulynas A, Salyga J, Malakauskiene R, et al. Physical and psychological dimensions of health-related quality of life among Lithuanian seamen. Acta Med Litu. 2007; 14: 50-53.

34. Sattler B. Environmental Health Risks: At home, at work, and in the community. Maurer FA, Smith CM. (Edits). Community Public Health Nursing Practice. Saunders 2009: 254-256.

35. Leszczyńska I, Jeżewska M, Grubman-Nowak M. Dynamics of stress as a predictor of health consequences in Polish drilling platform workers. Longitudinal study: part I. Int Marit Health. 2014; 65(1): 33-40, doi: 10.5603/MH.2014.0008, indexed in Pubmed: 24677126.

36. Lipowski M, Lipowska M, Peplińska A, et al. Personality determinants of health behaviours of merchant navy officers. Int Marit Health. 2014; 65(3): 158-165, doi: 10.5603/IMH.2014.0030, indexed in Pubmed: 25471165.

37. Romero-Paredes M, Reinoso-Barbero L, González-Gómez MF, et al. Improving cardiovascular health in Spanish seafarers. Int Marit Health. 2016; 67(1): 3-8, doi: 10.5603/IMH.2016.0002, indexed in Pubmed: 27029922. 